\title{
Вклад С. В. Чефранова и Г.Г. Швиттау в подготовку географических кадров в Воронеже
}

\author{
В. И. Шмыков $\bowtie$ \\ Воронежский государственный педагогический университет, Российская Федераџия \\ (394043, г. Воронеж, ул. Ленина, 86) \\ Поступила в редакиию 19.12.2019 \\ Принята к публикации 26.02.2020
}

\begin{abstract}
Аннотация: Цель - дать обзор основных этапов жизни и деятельности профессоров С. В. Чефранова и Г.Г. Швиттау, работавших в вузах города Воронежа в довоенный период и участвовавщих в становлении высшего географического образования. В современной географической среде эти ученые и педагоги мало известны, не осталось материалов о их деятельности в городе Воронеже, во время войны были уничтожены архивы вузов и нет теперь живых носителей памяти о них. Проанализированы их научно-педагогический уровень, вклад в подготовку географов для высшей и средней школы в ВГУ и ВГПИ. Профессор С. В. Чефранов являлся одним из соавторов учебников и хрестоматий по физической географии частей света, России и СССР, читал в ВГУ и ВГПИ курс «Физическая география СССР». Это был уровень географического центра образования СССР - Московского университета. Профессор Г. Г. Швиттау представитель научной экономической школы Санкт-Петербургского университета, внесший лично большой вклад в экономическую статистику, трудовое и социальное право. В Воронежском университете и Воронежском пединституте читал курс «Экономическая география зарубежных стран», работал над учебным пособием по курсу, руководил аспирантами. Пройдя замечательную научную школу, опыт работы по ведению научных исследований в Западной Европе, свободное владение десятком иностранных языков, опыт преподавания в Петербургском университете, он пользовался большим уважением преподавателей и студентов. С Воронежем связана загадочная история его интернирования во время войны в Восточную Европу и возвращение на работу в 1945 году. Идеи Г.Г. Швиттау и в настоящее время не утратили своей актуальности.
\end{abstract}

Ключевые слова: С.В. Чефранов, Г.Г. Швиттау, биографические данные, учебная и научная деятельность, труды, заслуги.

\section{Contribution S. V. Chefranov and G.G. Schwittau to the Training of Geographers in Voronezh}

\begin{abstract}
V.I. Shmikov $\bowtie$
Abstract: The goal is to give an overview of the main stages of life and work of professors S. V. Chefranov and G. G. Schwittau, who worked in the universities of Voronezh in the pre-war period and participated in the formation of higher geographical education. In the modern geographic environment, these scientists and teachers are little known, there were no materials about their activities in Voronezh, during the war archives of universities were destroyed and now there are no living carriers of memory about them. Their scientific and pedagogical level, contribution to the preparation of geographers for higher and secondary schools at the Voronezh State University and the All-Russian State Pedagogical Institute are analyzed. Professor S. V. Chefranov was one of the co-authors of textbooks and anthologies on the physical geography of parts of the
\end{abstract}

(С) Шмыков В.И., 2020

$\triangle$ E-mail: shmykov1949@mail.ru

(c) (i) Контент доступен под лицензией Creative Commons Attribution 4.0 License.

The content is available under Creative Commons Attribution 4.0 License. 
world, Russia and the USSR. He taught the course "Physical Geography of the USSR" at the Voronezh State University and the All-Russian State Pedagogical Institute. This was the level of the geographical center of education of the USSR - Moscow University. Professor G. G. Schwittau is a representative of the Scientific Economic School of St. Petersburg University, who personally made a great contribution to economic statistics, labor and social law. At the Voronezh University and the Voronezh Pedagogical Institute, he taught the course "Economic Geography of Foreign Countries" worked on a study guide for the course, and led graduate students. Having passed a wonderful scientific school, experience in conducting research in Western Europe, fluency in a dozen foreign languages, and teaching experience at St. Petersburg University, he was highly respected by teachers and students. The mysterious history of his internment during the war in Eastern Europe and his return to work in 1945 is connected with Voronezh. Ideas G. G. Schwittau and at present have not lost their relevance.

Key words: S. V. Chefranov, G. G. Schwittau, curriculum vitae, teaching and research activities, works, services.

С начальным этапом становления вузовской географии в ВГУ и ВГПИ связана учебная деятельность профессоров Георгия Георгиевича Швиттау и Сергея Васильевича Чефранова. Они уже в начале прошлого века стали известными специалистами в разных областях географии и имели большой опыт преподавательской деятельности. Этих ученых с полным основанием можно назвать «связующим звеном» между дореволюционной и советской географической наукой, академической географией и новыми только формирующимися направлениями. Они оказали, несомненно, большое влияние на формирование новых кадров географов как для средней, так и для высшей школы нашего региона.

Сергей Васильевич Чефранов (1872-1952), известный педагог, физико-географ, наш земляк, родился в городе Воронеж. Выпускник естественно-исторического отделения физико-математического факультета Московского университета (1896), один из лучших учеников профессора Д. Н. Анучина. Позже работал учителем в московских школах. На сайте Ярославского педуниверситета говорится о продолжении им образования в Западной Европе. Начиная с 1900 года, он вместе со своими бывшими однокурсниками С. Г. Григорьевым, А. А. Крубером и А. С. Барковым составил «московскую четверку» («Четырех разбойников» по версии Симонова Ю.Г.) молодых тогда преподавателей, задумавших и совершивших буквально переворот в школьной географии [5].

Со слов А. С. Баркова, они хотели сделать уроки географии интересными, не скучными, не похожими на сухие школьные учебники ${ }^{1}$. Четверка педагогов решила издать хрестоматию, основан-

\footnotetext{
${ }^{1}$ Осипова Ю.А. Знакомьтесь с еще одним тульским географом. Александр Сергеевич Барков. Доступно: https://redcub.diary.ru/p207124855.htm?oam (дата обращения: 20.12.2019)
}

ную на описаниях путешествующих, выбирая из них то, что им казалось наиболее типичным для той или иной страны и более интересным. Их желание поддержал Д. Н. Анучин, предоставив возможность пользоваться книгами, фотографиями, альбомами и другими пособиями и материалами университетского кабинета географии. За 19001904 года были составлены и изданы семь иллюстрированных географических хрестоматий: «Азия», «Америка», «Африка», «Европа», «Австралия». «Азиатская Россия» и «Европейская Россия» - объемом по 500-700 страниц. Каждая имела от 40 до 100 иллюстраций. Все они были высоко оценены в печати и выдержали по нескольку изданий. Это был большой успех.

Из воспоминаний А.С. Баркова также известно, что Д. Н. Анучин высказал мысль о новой непростой задаче: «Теперь надо вам приняться за учебники. Вы ведь хорошо сработались». Первый учебник «Начальный курс географии» вышел в 1903 году. Далее в 1905 году вышел второй учебник: «Курс географии европейских стран», а в 1908 году третий: «Курс географии Европы». Завершили, как писал А.С. Барков, «самым трудным и самым сложным учебником - учебником географии России». Учебник вышел во время первой Мировой войны, скромный по оформлению и не имел широкого распространения. Предыдущие же учебники выдержали соответственно 16, 14 и 10 изданий.

По общему признанию, учебники произвели переворот в обучении географии. Они давали не только описание, но и объяснение географических явлений и закономерностей, содействовали их пониманию, развивали интерес учащихся к географии. В середине 50-х годов Н. Н. Баранский назовет их одними из лучших в истории школьной учебной географической литературы [5]. Лучшим памятником С. В. Чефранову служат сохранившиеся в зональной библиотеке ВГУ дореволюцион- 
ные издания хрестоматий по Европе, Азии, Америке, Европы.

Будучи опытным педагогом, имеющим опыт работы в школе и в МГУ С. В. Чефранов в 1934 году был приглашен проф. Б. П. Дитмаром для чтения курса по физической географии СССР в ВГУ и ВГПИ [3]. Работал он, вероятно, до конца учебного года в 1939 году, т.е. до перехода Б. П. Дитмара в Крымский пединститут. Важно то, что он был первым кто читал курс географии СССР, опираясь на широчайший географический кругозор, опыт работы в школе и будучи соавтором первых вузовских учебников. В музее ВГПУ сохранилась в отличном состоянии фотография Чефранова С. В. с первым выпуском заочного отделения географов 1937 года. С 1940 года С. В. Чефранов работает в Московском педагогическом институте им. В.П. Потемкина. В 1941 году он получает звание профессора и заведует кафедрой физической географии.

Георгий Георгиевич Швиттау (23.04.18751950) родился в городе Санкт-Петербург в семье служащего. Основные этапы его жизни и научнопедагогический деятельности отражены в работах С. Н. Карельской, Г. М. Васильевой, А. М. Лушникова и др. [1, 3, 4]. В 1902 году Швиттау закончил юридический факультет Санкт-Петербургского университета с дипломом первой степени, выбрав экономическую специализацию. Его учили знаменитые экономисты: П.И. Георгиевский (18571938), А. А. Исаев (1850-1924), М. И. Туган-Барановский (1865-1919), В. Г. Яроцкий (1855-1917). По рекомендации П.И. Георгиевского Г.Г. Швиттау был оставлен при университете для подготовки к профессорскому званию по кафедре политической экономии с предоставлением двух работ: по гражданскому праву и по экономической географии. С 1905 года в течение почти двух лет он находился в заграничной командировке (в основном в Берлине и Лондоне), в результате чего появилась работа «Государственный бюджет в Англии (Историкосравнительный очерк)», посвященная истории и бюджетному праву Англии.

В 1908 году, после сдачи магистерского экзамена, Г. Г. Швиттау занял должность приват-доцента Петербургского университета по кафедре политической экономии и статистики, где начал читать курс лекций «Экономическая статистика». Ранее эту дисциплину читали в некоторых средних и высших учебных заведениях (коммерческих, земледельческих и др.) только в качестве составной части курса экономической географии. В это же вре- мя Георгий Георгиевич принимал активное участие в заседаниях научного кружка М. И. Туган-Барановского и статистического семинария И. И. Кауфмана. В этот период Г. Г. Швиттау написаны три работы по экономической статистике. Статья «Экономическая статистика», посвященная истории развития статистики и описанию ее положения в начале XX века, в 1910 году была включена в книгу «Введение в экономическую статистику». Частью книги стала другая работа - «О выборочном методе в статистике», раскрывающая предпосылки и логические основания использования выборочного метода наблюдения, особенности этого статистического приема, правила его использования и методы критической оценки полученных результатов. «Введение в экономическую статистику»- первое в нашей стране систематическое изложение методологических вопросов этой отрасли знаний [3].

В 1915 году в Московском университете Швиттау защитил докторскую диссертацию на тему «Квалифицированный труд» и был впоследствии утвержден в качестве доктора политэкономии и статистики.

В 1916 году Г. Г. Швиттау переходит на должность профессора в Новороссийский университет города Одесса. В 1919 году в смутное время Гражданской войны его отправляют, если верить материалам личного дела, в научную командировку за границу [4]. Непонятно только, представители какой власти приняли такое решение: большевики или белые. За границей он жил сначала в Англии, а затем во Франции, Германии, Италии, Канаде и США. Прекрасное владение иностранными языками и европейская известность позволили ему достаточно быстро адаптироваться на чужбине и даже опубликовать ряд научных работ на английском и немецком языках. В конце 1921 году в судьбе ученого произошел еще один крутой поворот. Он согласился занять должность ученого специалиста при торгпредстве СССР в Берлине, а затем в Лондоне и Гамбурге. Этому есть вполне рациональное объяснение. Несмотря на то, что в Европе Швиттау не был «чужим», он являлся русским патриотом, а в России остались его близкие. Кроме того, НЭП дал основание бывшему легальному марксисту считать, что советская политика поворачивается в правильное эволюционное русло [4]. В 1929 году он возвращается на родину, где начинает работать в Академии сельскохозяйственных наук им. В. И. Ленина. 
С 1934 по 1937 год Швиттау занимал должность профессора и заведующего кафедрой организации и статистики советской торговли в Иркутском институте советской торговли, где обратился к правовой стороне торговой деятельности. После закрытия института Г. Г. Швиттау назначают профессором кафедры экономической географии Воронежского госуниверситета и одновременно заведующим кафедрой экономической географии Воронежского педагогического института [2]. В этот период он был лишен возможности заниматься проблемами правового регулирования трудовых отношений за рубежом, так как считалось, что трудового права на Западе просто нет, а трудовые отношения там регулируются нормами гражданского права.

В статье А. М. Лушникова приводится интересный факт о том, что в ноябре 1939 года в Высшую аттестационную комиссию (ВАК) были представлены документы из Воронежского университета на присуждение Швиттау ученой степени доктора экономических наук без защиты. Но это решение не было принято по причине того, что Воронежский университет имеет слишком низкий ранг по сравнению с МГУ и другими столичными вузами. И это при том, что Швиттау защитил докторскую диссертацию еще в 1915 году. и именно в Московском университете.

Интересен еще и такой факт, приведенный в юбилейном сборнике статей ВГУ в 2004 году, где приведены сведения, что для устранения большого дефицита квалифицированных вузовских преподавателей весь первый выпуск 1939 года в количестве 15 человек был целиком ориентирован на научно-педагогическую работу в вузы страны. Были оставлены при кафедре экономической географии для преподавательской работы М.М. Эфpac, И. И. Тищенко, В. Л. Ильинская, А. Мандрук, Иоффе, Т. А. Русанова и поступлению их в аспирантуру к проф. К.Н. Миротворцеву и проф. Г. Г. Швиттау [2]. В начале 1941-1942 учебного года в условиях прифронтовой полосы учебный процесс в университете не прерывался. Часть преподавателей и студентов была эвакуирована, а по воспоминанию проф. Гришина Г. Т. по разным обстоятельствам из числа сотрудников кафедры выбыли проф. Г. Г. Швиттау и ассистент М. Эфрас [2]. Мы нашли следы Марка Моисеевича Эфроса, до войны он был оставлен в аспирантуре, вел заня-

2 Толстов В. Одиссея Марка Эфроса / Заполярная правда 16.04.2004. Доступно: https://memorial.krsk.ru/ Public/00/20040416.htm (дата обращения: 20.12.2019) тия со студентами и являлся зам.декана географического факультета ${ }^{2}$. С начала войны, будучи негодным к строевой, был направлен на должность заместителя прокурора Лосевского района Воронежской области. После войны он пытался восстановиться на работу в ВГУ, но не был принят. Можно предположить, что он был одним из аспирантов Г.Г. Швиттау. Диссертацию М. Эфрос не защищал, и впоследствии долго работал директором школы в городе Норильск.

Г.Г. Швиттау в ВГПИ вел курс «Экономическая география зарубежных стран». М. А. Зубащенко в своих воспоминаниях пишет о его работе над учебным пособием по данной дисциплине. Это пособие так и не было опубликовано. Установлено, что в ВГПИ первым аспирантом Швиттау в 19381939 годах была П.И. Кирнос, которая только в 1956 году защитила кандидатскую диссертацию.

При захвате Воронежа фашистами в июле 1942 году в результате пожара погибли почти все рукописи ученого, а сам он был отправлен сначала в Познань, а затем в Прагу, где находился до мая 1945 года. А. М. Лушников, анализируя материалы личного дела Швиттау, пишет, что возникают вопросы: в качестве кого и каким образом он там оказался [4]. Далее говорится, что в анкете «род занятий за этот период», он указал как «безработный». Можно предположить, что Швиттау вряд ли был отправлен в Германию в качестве пленного или бесплатной рабочей силы вследствие его преклонного возраста и профессии. Скорее всего, он был отправлен в качестве фольксдойче (немца, родившегося и выросшего за пределами исторической родины) на землю предков. В этой связи более понятным становится и положение безработного, и нахождение в Праге. После мая 1945 года Швиттау был репатриирован и восстановлен в прежних должностях в воронежских вузах [4]. В архиве ВГПИ найден приказ Министерства просвещения, датируемый сентябрем 1943 года об увольнении проф. Швиттау с должности заведующего кафедрой экономической географии. Приказов о восстановлении в должности как в ВГПИ, так и в ВГУ в архивах не обнаружено. При этом он не был репрессирован и, судя по всему, даже не содержался в фильтрационном лагере [4]. Самым вероятным образом выглядит сотрудничество Г. Г. Швиттау с советскими органами безопасности, причем еще с «торгпредского периода» 20-х годов. Как отмечает А. М. Лушников с этим, по видимому, связана история с неявкой его в 1941-1942 учебному году на работу и ин- 
тернирование в 1942 году при вторжении немецких войск в город Воронеж. Однако документы на этот счет отсутствуют и что-либо определенно утверждать нельзя.

Во второй половине 1946 года Г.Г. Швиттау переходит на работу в Ярославский педагогический институт, где занимает сначала должность профессора, а с 1947 года заведующего кафедрой экономической географии. В июне 1948 года ВАК утверждает его в ученом звании профессора, а в декабре 1949 года его принимают в число действительных членов Географического общества СССР. Г. Г. Швиттау до последних дней оставался профессором Ярославского педагогического института.

Г. Г. Швиттау был ученым огромной эрудиции. Он опубликовал около 220 работ, в том числе 11 монографий, а также несколько десятков книг и статей за рубежом, преимущественно в Англии и Германии [6]. Его труды в силу широты постановки проблемы и комплексного подхода и в настоящее время представляют определенный научный интерес.

Итак, С. В. Чефранов и Г.Г. Швиттау оказали существенное влияние на становление географического образования, задавая высокую планку его уровня в высшей школе. А некоторые их научные подходы не потеряли актуальности и в настоящее время.

\section{Основные труды профессора С. В. Чефранова}

Азия: иллюстрированный географический сборник, составленный А. Крубером, С. Григорьевым, А. Барковым, С. Чефрановым. Изд. 2-е. Москва: т-во И.Н. Кушнерев и К우 1904.545 с.

Америка: иллюстрированный географический сборник, составленный А. Крубером, С. Григорьевым, А. Барковым, С. Чефрановым. Изд. 2-е. Москва: т-во И.Н. Кушнерев и Кㅇ 1905. 628 с.

Африка: иллюстрированный географический сборник, составленный А. Крубером, С. Григорьевым, А. Барковым и С. Чефрановым. Москва: т-во И.Н. Кушнерев и К우 1902.512 с.

География СССР: Учебник для 7-го класса семилетней и средней школы. 8-е изд., перераб. Москва: Учпедгиз, 1949. 200 с.

\section{Основные труды профессора Г.Г. Швиттау}

Профессии и занятия населения: опыт критико-методологического исследования в области экономической статистики. Санкт-Петербург: Типография Ю. Н. Эрлих, 1909. 324 с.

Введение в экономическую статистику. СанктПетербург: Типография Ю.Н. Эрлих, 1910. 144 с.
Промышленные конфликты: Экономическое исследование в области современной политики труда на Западе. Санкт-Петербург: Типография Ю.Н. Эрлих, 1911. 486 с.

Трудовая помощь в России. Петроград: Типография А. Э. Коллинс, 1915. Ч. 1. 216 с.

Трудовая помощь в России. Петроград: Типография А.Э. Коллинс, 1915. Ч. 2. 600 с.

Квалифицированный труд. Проблема детского труда. Петроград: Типография А.Э. Коллинс, 1915. Ч. 1.424 c.

\section{СПИСОК ЛИТЕРАТУРЫ}

1. Васильева Г. М. Идея «мирового хозяйства»: традиция Гете в сочинениях Г.Г. Швиттау // Вестник Новосибирского государственного университета экономики и управления, 2014, № 4, с. 233-242.

2. Гришин Г.Т., Поросенков Ю.В. Кафедра социально-экономической географии и регионоведения: история и современность // Вестник Воронежского государственного университета. Серия: География. Геоэкология, 2004, № 2, с. 42-63.

3. Карельская С. Н. Г. Г. Швиттау - основатель российской экономической статистики // Вопросы статистики, 2009, № 11, с. 75-82.

4. Лушников А. М., Лушникова М.В. Связующее звено: жизнь и научное наследие Н.Н. Кравченко и Г.Г. Швиттау // Вестник трудового права и права социального обеспечения, 2006, вып. 1, с. 116-137.

5. Симонов Ю. Г. История географии в Московском университете: события и люди. Москва, Городец, 2008, т. $1.504 \mathrm{c}$.

6. Федотов В.И., Куролап С.А., Хрипякова В.Я. Факультет географии и геоэкологии Воронежского университета на рубеже веков (1934-2004) // Вестник Воронежского государственного университета. Серия География. Геоэкология, 2004, №2, с. 42-63.

\section{REFERENCES}

1. Vasil'eva G. M. Ideya "mirovogo khozyaystva": traditsiya Gete v sochineniyakh G. G. Shvittau [The idea of "world economy": Goethe's tradition in the works of G. G. Schwittau]. Vestnik Novosibirskogo gosudarstvennogo universiteta ekonomiki i upravleniya, 2014, no. 4, pp. 233-242. (In Russ.)

2. Grishin G. T., Porosenkov Yu. V. Kafedra sotsial'noekonomicheskoy geografii i regionovedeniya: istoriya $\mathrm{i}$ sovremennost' [Department of Socio-Economic Geography and Regional Studies: History and Present]. Vestnik Voronezhskogo gosudarstvennogo universiteta. Seriya: Geografiya. Geoekologiya, 2004, no. 2, pp. 42-63. (In Russ.)

3. Karel'skaya S. N. G. G. Shvittau - osnovatel' rossiyskoy ekonomicheskoy statistiki [G. G. Schwittau - founder of Russian economic statistics]. Voprosy statistiki, 2009, no. 11, pp. 75-82. (In Russ.) 
4. Lushnikov A. M., Lushnikova M. V. Svyazuyushchee zveno: zhizn' i nauchnoe nasledie N.N. Kravchenko i G. G. Shvittau [Link: life and scientific heritage of N. N. Kravchenko and G. G. Schwittau]. Vestnik trudovogo prava i prava sotsial'nogo obespecheniya, 2006, v. 1, pp. 116-137. (In Russ.)

5. Simonov Yu. G. Istoriya geografii v Moskovskom universitete: sobytiya i lyudi [History of geography at Mos-

\section{КОНФЛИКТ ИНТЕРЕСОВ}

Автор декларирует отсутствие явных и потенциальных конфликтов интересов, связанных с публикацией настоящей статьи.

Шмыков Виктор Ильич

кандидат географических наук, доцент кафедры географии и туризма Воронежского государственного педагогического университета, г. Воронеж, Российская Федерация, E-mail: $\underline{\text { shmykov1949@mail.ru }}$ cow University: events and people]. Moskow, Publ. Gorodets, 2008, v. 1.504 p. (In Russ.)

6. Fedotov V.I., Kurolap S. A., Khripyakova V. Ya. Fakul'tet geografii i geoekologii Voronezhskogo universiteta na rubezhe vekov (1934-2004) [Faculty of Geography and Geoecology, Voronezh University at the turn of the century (1934-2004)]. Vestnik Voronezhskogo gosudarstvennogo universiteta. Seriya Geografiya. Geoekologiya, 2004, no. 2, pp. 42-63. (In Russ.)

\section{CONFLICT OF INTEREST}

The author declares no information of obvious and potential conflicts of interest related to the publication of this article.

Viktor I. Shmykov

Cand. Sc. (Geogr.), Assoc. Prof. at the Department of Geography and Tourism, Voronezh State Pedagogical University, Voronezh, Russian Federation, e-mail: shmykov1949@mail.ru 